\title{
Acute respiratory failure due to hemothorax after posterior correction surgery for adolescent idiopathic scoliosis: a case report
}

\author{
Yoji Ogura $^{1 \dagger}$, Kota Watanabe $^{2 \dagger}$, Naobumi Hosogane ${ }^{1}$, Yoshiaki Toyama $^{1 \dagger}$ and Morio Matsumoto ${ }^{1 * \dagger}$
}

\begin{abstract}
Background: Although posterior correction and fusion surgery using pedicle screws carries the risk of vascular injury, a massive postoperative hemothorax in a patient with adolescent idiopathic scoliosis (AIS) is quite rare. We here report a case of a 12-year-old girl with AlS who developed a massive postoperative hemothorax.

Case presentation: The patient had a double thoracic curve with Cobb angles of $63^{\circ}$ at T2-7 and $54^{\circ}$ at $\mathrm{T} 7-12$. Posterior correction and fusion surgery was performed using a segmental pedicle screw construct placed between $\mathrm{T} 2$ and T12. Although the patient's respiration was stable during the surgery, 20 minutes after removing the trachea tube, the patient's pulse oximetry oxygen saturation suddenly decreased to $80 \%$. A contrast CT scan showed a massive left hemothorax, and a drainage tube was quickly inserted into the chest. The patient was re-intubated and a positive end-expiratory pressure of $5 \mathrm{cmH}_{2} \mathrm{O}$ applied, which successfully stopped the bleeding. The patient was extubated 4 days after surgery without incident. Based on contrast CT scans, it was suspected that the hemothorax was caused by damage to the intercostal arteries or branches during pedicle probing on the concave side of the upper thoracic curve. Extensive post-surgical blood tests, echograms, and CT and MRI radiographs did not detect coagulopathy, pulmonary or vascular malformation, or any other possible causative factors.
\end{abstract}

Conclusion: This case underscores the potential risk of massive hemothorax related to thoracic pedicle screw placement, and illustrates that for this serious complication, respiratory management with positive airway pressure, along with a chest drainage tube, can be an effective treatment option.

\section{Background}

Hemothorax is usually related to chest trauma or to medical procedures such as central venous line insertion, thoracentesis, pleural biopsy, or intrathoracic surgeries that can injure lung parenchyma or intrathoracic vessels such as the intercostal or internal mammary arteries and their branches $[1,2]$. Postoperative hemothorax has been reported as a complication associated with anterior procedures and posterior thoracoplasty [1,3] in correction and fusion surgeries for scoliosis. The incidence of hemothorax in anterior scoliosis surgery is reported to be $1-2.2 \%[2-4]$.

\footnotetext{
* Correspondence: morio@a5.keio.jp

${ }^{\dagger}$ Equal contributors

${ }^{1}$ Department of Orthopaedic Surgery, Keio University School of Medicine, Tokyo, Japan

Full list of author information is available at the end of the article
}

Hemothorax may be caused by surgical procedures such as releasing the pleurae from the vertebrae, or the removal and curettage of intervertebral discs and cartilage end plates. The placing of pedicle screws in the course of posterior correction and fusion surgery carries a risk of vascular injury. However, the occurrence of hemothorax associated with corrective surgery is as low as $0.1 \%$ [5-7] in patients with adolescent idiopathic scoliosis (AIS). A review article of the Scoliosis Research Society morbidity and mortality database also showed pulmonary complication, which included complication other than hemothorax, was $0.9 \%$ [8]. All previously reported incidents of postoperative hemothorax were treated by observation without additional intervention.

Here we report the case of a patient with AIS who developed a massive hemothorax after posterior correction and fusion surgery using a pedicle screw construct. The

\section{Biomed Central}

(c) 2013 Ogura et al.; licensee BioMed Central Ltd. This is an Open Access article distributed under the terms of the Creative Commons Attribution License (http://creativecommons.org/licenses/by/2.0), which permits unrestricted use, distribution, and reproduction in any medium, provided the original work is properly cited. 
hemothorax induced acute respiratory failure and required the insertion of a chest drainage tube.

\section{Case presentation}

A 12-year-old girl with progressive trunk deformity was referred to our department. She had been diagnosed with AIS at 11 years old, and had started brace treatment. A full time underarm type brace was applied before surgery. The Cobb angles before brace treatment were $36^{\circ}$ at $\mathrm{T} 2-7$ and $35^{\circ}$ at $\mathrm{T} 7-12$. The curves were corrected to $31^{\circ}$ and $27^{\circ}$ with the correction rate of $15 \%$ and $22 \%$, respectively after application of the brace. Because the deformity progressed in spite of the brace treatment, she was referred to our department to undergo surgical treatment. Physical examination found a prominent rib hump on the right side, and her right shoulder was slightly elevated. There were no abnormalities in her extremities or neurological examination. The patient weighed $31.8 \mathrm{~kg}(-1.20 \mathrm{SD})$, with a height of $132.5 \mathrm{~cm}(-2.37 \mathrm{SD})$.

Radiographs showed scoliosis of $63^{\circ}$ at T2-7 and $54^{\circ}$ at T7-12, and kyphosis of $25^{\circ}$ at T5-12 (Figure 1). Supine side-bending radiographs showed scoliosis of $50^{\circ}$ at T2-7 and $35^{\circ}$ at $\mathrm{T} 7-12$, and the curve flexibilities were $21 \%$ and $35 \%$, respectively. The Lenke classification was type 2AN. Three-dimensional CT images showed no congenital deformity of the thoracic or lumbar spine. The mean pedicle width between T2-12 was $3.4 \pm 1.3 \mathrm{~mm}$ (1.5$5.2 \mathrm{~mm})$ on the right side, and $3.5 \pm 0.9 \mathrm{~mm}(2.1-4.8 \mathrm{~mm})$

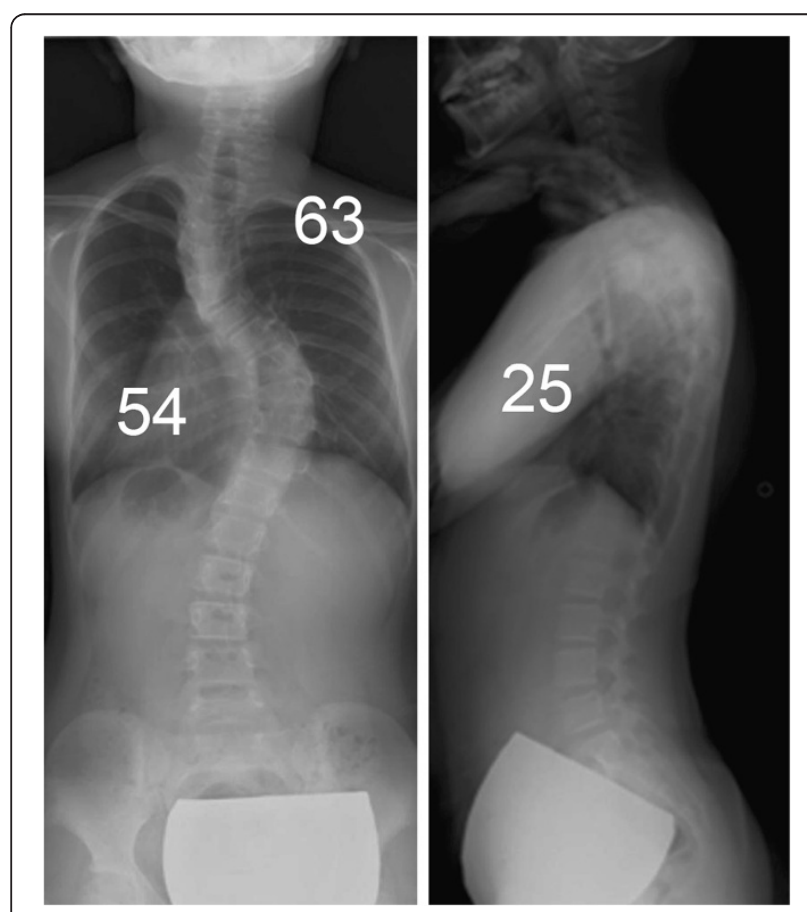

Figure 1 Standing x-rays. Standing $x$-rays show scoliosis of $63^{\circ}$ at $\mathrm{T} 2-7$ and $54^{\circ}$ at $\mathrm{T} 7-12$, and kyphosis of $25^{\circ}$ at $\mathrm{T} 5-12$. on the left side. The narrowest pedicle width was $1.5 \mathrm{~mm}$ at T3 and T4 on the right side, and $2.1 \mathrm{~mm}$ at T8 on the left side. Laboratory data showed no coagulation disorders (PT, $10.6 \mathrm{sec}$; APTT, $34.4 \mathrm{sec}$ ), and a pulmonary function test revealed normal lung function $(\% \mathrm{VC}, 84 \%$; $\left.\% \mathrm{FEV}_{1.0}, 93 \%\right)$.

The patient underwent posterior correction and fusion surgery with a segmental pedicle screw construct at T212. After the posterior elements of the thoracic spine were meticulously exposed, pedicle screws were placed segmentally using a ball-tip probe technique [9]. No obvious pedicle perforation was noted during screw placements. Ponte osteotomies were performed between T3 and T6, since the proximal curve had low flexibility. The curves were corrected with a rod applied on the concave side of the main thoracic curve and in situ bending of the rod followed by a graft of local bone. The surgery took 184 minutes, with an estimated blood loss of 400 $\mathrm{ml}$. The scoliosis was corrected to $10^{\circ}$ and $18^{\circ}$, with correction rates of $84 \%$ and $67 \%$, respectively (Figure 2).

The patient's respiratory status was stable during the surgery. After confirming $100 \% \mathrm{SpO}_{2}$, the patient was extubated without incident. A chest $\mathrm{x}$-ray taken just before extubation was normal. However, within $20 \mathrm{mi}-$ nutes after removing the tube, $\mathrm{SpO}_{2}$ dramatically decreased to $80 \%$ even though the patient was placed on

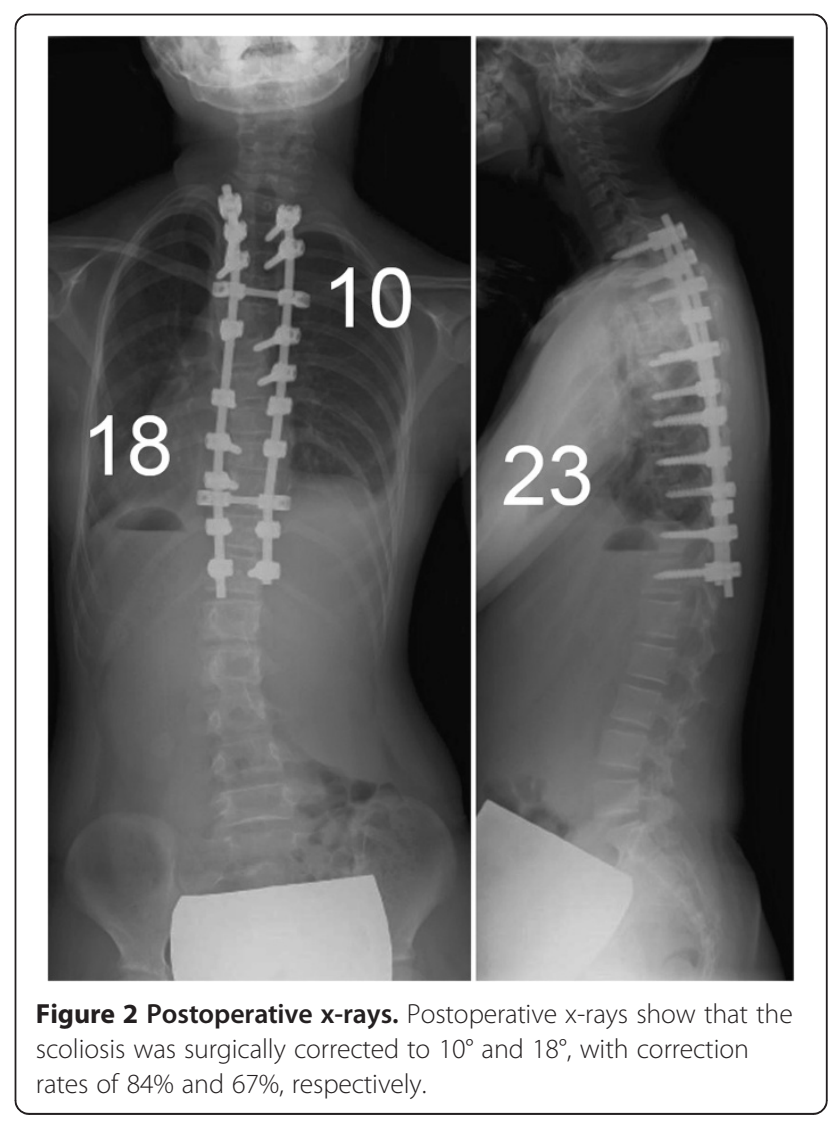


$100 \%$ oxygen. A chest x-ray taken 25 minutes after surgery showed massive opacification in the left thorax (Figure 3). Contrast CT images of the chest revealed a massive hemothorax in the left pleural space, which was on the convex side of the upper thoracic curve (Figure 4). However, CT images did not show a definitive arterial rupture or malpositioned pedicle screw.

Since the patient's $\mathrm{SpO}_{2}$ remained as low as $80-85 \%$ even with oxygen treatment, a drainage tube was inserted in the chest 110 minutes after surgery, and $400 \mathrm{ml}$ blood was drained. To prevent additional hemorrhage, an intubation tube was inserted again, and then $5 \mathrm{cmH}_{2} \mathrm{O}$ positive end-expiratory pressure was applied, which stopped blood drainage from the chest. The tracheal and drainage tubes were removed four days after surgery. There were no signs of dyspnea or deteriorating $\mathrm{SpO}_{2}$ after extubation, even though the patient was no longer on oxygen. Chest CT images taken one week after surgery showed no pleural effusion. The pulmonary function showed $88 \%$ of $\%$ vital capacity (\%VC) and 95\% of \% predicted forced expiratory volume in one second $\left(\% \mathrm{FEV}_{1.0}\right)$ two years after surgery.

\section{Conclusions}

Postoperative hemothorax is quite rare in posterior correction and fusion surgery for AIS. A systematic review of 1666 AIS patients who underwent posterior surgery using pedicle screw constructs identified only one hemothorax after surgery [6]. Another review of 5654

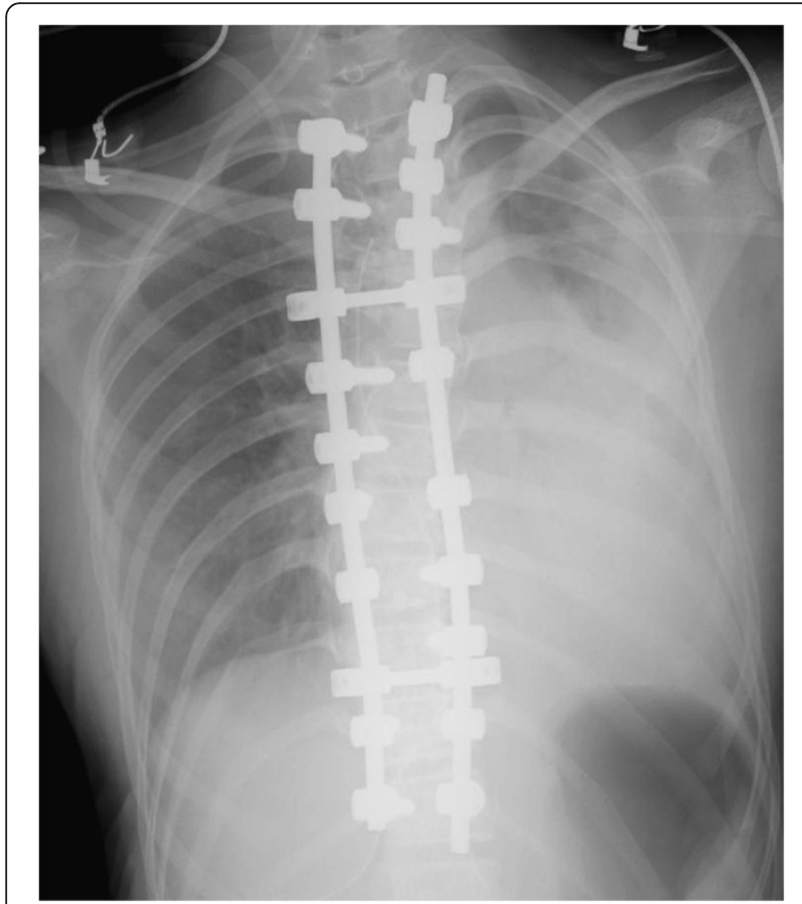

Figure 3 A chest x-ray taken $\mathbf{2 0}$ minutes after extubation. A chest $x$-ray film taken twenty minutes after extubation shows a massive hemothorax in the left lung field.

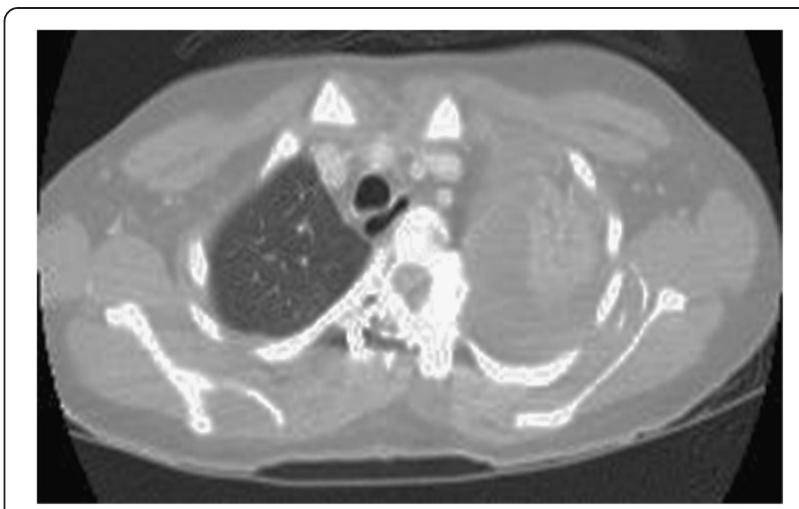

Figure 4 A postoperative chest $C T$ image. A postoperative $C T$ image of the chest shows a massive hemothorax in the left pleural space.

AIS patients who underwent posterior surgery also found only one hemothorax after surgery [5]. In both hemothorax cases, the hemorrhage was not substantial, and the patients were observed without further intervention.

To our knowledge, this is the first recorded case of an AIS patient who developed acute respiratory failure due to massive hemorrhage in the pleural space after posterior surgery with a pedicle screw construct, and who required the insertion of a drainage tube in the chest. Postoperative hemothorax appears to be more common in scoliosis associated with muscle dystrophy than in AIS. Modi et al. attributed this to spinal osteoporosis in patients with muscle dystrophy, which increases the risk of the vertebral body's lateral and anterior cortical walls being breached while probing the pedicle and inserting pedicle screws [1]. They also speculated that fragility of the blood vessels, including the intercostal arteries and their branches, is a risk factor for hemothorax [1].

It was suspected that the hemothorax in our patient was caused by damage to a segmental vessel when probing the pedicle on the convex side of the proximal

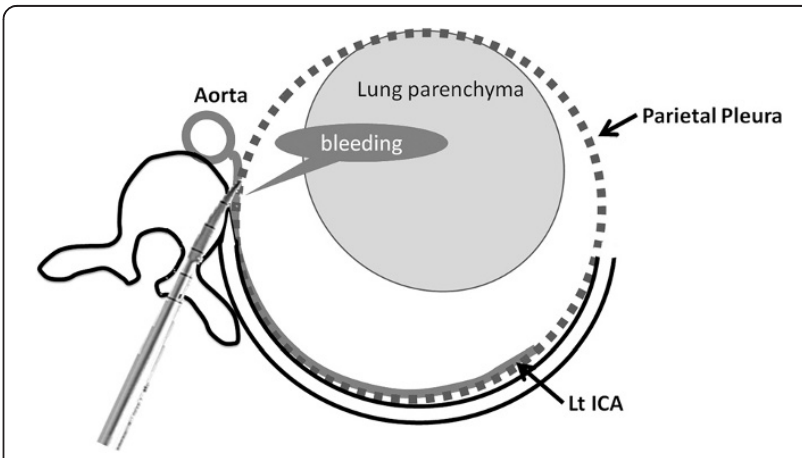

Figure $\mathbf{5}$ Vascular anatomy at the pleurae. Left Intercostal Arteries (ICAs), which branch directly from the aorta, supply the posterior part of the pleurae along each rib. Pedicle probing may have injured the left ICAs, which run near the vertebrae. 
thoracic curve, since contrast CT images showed the hematoma pushing the lung away from the vertebrae in this area. Anatomically, the internal mammary arteries and their branches supply the anterior part of the pleurae, while the intercostal arteries and their branches supply the posterior part of the pleurae along each rib (Figure 5). The hemothorax may have been caused by the rupture of an intercostal artery or arterial branch. Extensive CT, MRI, and echogram evaluation after surgery did not detect any other causative factors, such as coagulopathy or pulmonary or vascular malformation.

The hemothorax appeared on a chest $\mathrm{x}$-ray taken twenty minutes after extubation. Bleeding from vessels injured during pedicle probing might have been suppressed during surgery by the positive airway pressure maintained by ventilation. After extubation, the negative intrathoracic pressure introduced by spontaneous inspiration might have allowed the injured vessel to start bleeding. The positive end-expiratory pressure, $5 \mathrm{cmH}_{2} \mathrm{O}$, that we used in this case is the standard pressure used to keep the lung from collapsing at the end-expiratory phase [10]; the compressive force created by positive airway pressure successfully stopped the bleeding.

In a previous report of hemothorax after surgery to implant a cardiac pace maker, this method was reported to be effective for initially managing hemothorax if vital signs are stable [11]. If positive airway pressure does not stop the bleeding, catheter embolization or direct application of a hemostat by thoracotomy should be considered [12].

This case illustrates that placing thoracic pedicle screws carries a risk of massive hemothorax that may become apparent after extubation, and confirms the effective use of re-intubation with positive end-expiratory pressure, along with chest drainage, to treat this serious complication.

\section{Consent}

Written informed consent was obtained from the parents of the patient for publication of this case report and any accompanying images. A copy of the written consent is available for review from the Editor-in-Chief of this journal.

\section{Competing interests}

The authors declare that they have no competing interests.

\section{Authors' contributions}

YO, KW, and MM made substantial contributions to the conception and design, and the acquisition, analysis, and interpretation of data. They were also involved in drafting and revising the manuscript. NH and YT contributed to the conception and design, and performed critical revision of the manuscript. All authors read and approved the final manuscript.

\section{Author details}

'Department of Orthopaedic Surgery, Keio University School of Medicine, Tokyo, Japan. ${ }^{2}$ Department of Advanced Treatment for Spine and Spinal Cord Disorders, Keio University School of Medicine, Tokyo, Japan.
Received: 16 January 2013 Accepted: 1 April 2013

Published: 11 April 2013

\section{References}

1. Modi HN, Suh SW, Hong JY, Cho JW, Park JH, Yang JH: Treatment and complications in flaccid neuromuscular scoliosis (Duchenne muscular dystrophy and spinal muscular atrophy) with posterior-only pedicle screw instrumentation. European spine journal: official publication of the European Spine Society, the European Spinal Deformity Society, and the European Section of the Cervical Spine Research Society 2010, 19(3):384-393.

2. Grossfeld S, Winter RB, Lonstein JE, Denis F, Leonard A, Johnson L: Complications of anterior spinal surgery in children. J Pediatr Orthop 1997, 17(1):89-95.

3. Shapiro G, Green DW, Fatica NS, Boachie-Adjei O: Medical complications in scoliosis surgery. Curr Opin Pediatr 2001, 13(1):36-41.

4. Weis JC, Betz RR, Clements DH 3rd, Balsara RK: Prevalence of perioperative complications after anterior spinal fusion for patients with idiopathic scoliosis. J Spinal Disord 1997, 10(5):371-375.

5. Gautschi OP, Schatlo B, Schaller K, Tessitore E: Clinically relevant complications related to pedicle screw placement in thoracolumbar surgery and their management: a literature review of 35,630 pedicle screws. Neurosurg Focus 2011, 31(4):E8.

6. Hicks JM, Singla A, Shen FH, Arlet V: Complications of pedicle screw fixation in scoliosis surgery: a systematic review. Spine 2010, 35(11):E465-E470.

7. Levine DS, Dugas JR, Tarantino SJ, Boachie-Adjei O: Chance fracture after pedicle screw fixation. A case report. Spine 1998, 23(3):382-385. discussion 386.

8. Fu KM, Smith JS, Polly DW, Ames CP, Berven SH, Perra JH, Glassman SD, McCarthy RE, Knapp DR, Shaffrey Cl: Morbidity and mortality associated with spinal surgery in children: a review of the scoliosis research society morbidity and mortality database. J Neurosurg Pediatr 2011, 7(1):37-41.

9. Watanabe K, Matsumoto M, Tsuji T, Ishii K, Takaishi H, Nakamura M, Toyama Y, Chiba K: Ball tip technique for thoracic pedicle screw placement in patients with adolescent idiopathic scoliosis. J Neurosurg Spine 2010, 13(2):246-252.

10. Brower RG, Lanken PN, MacIntyre N, Matthay MA, Morris A, Ancukiewicz M, Schoenfeld D, Thompson BT: Higher versus lower positive end-expiratory pressures in patients with the acute respiratory distress syndrome. N Engl J Med 2004, 351(4):327-336.

11. Lai CH, Chen JY, Wu HY, Wen JS, Yang YJ: Successful conservative management with positive end-expiratory pressure for massive haemothorax complicating pacemaker implantation. Resuscitation 2007, 75(1):189-191.

12. Hunt PA, Greaves I, Owens WA: Emergency thoracotomy in thoracic trauma-a review. Injury 2006, 37(1):1-19.

doi:10.1186/1471-2474-14-132

Cite this article as: Ogura et al:: Acute respiratory failure due to hemothorax after posterior correction surgery for adolescent idiopathic scoliosis: a case report. BMC Musculoskeletal Disorders 2013 14:132.

\section{Submit your next manuscript to BioMed Central and take full advantage of:}

- Convenient online submission

- Thorough peer review

- No space constraints or color figure charges

- Immediate publication on acceptance

- Inclusion in PubMed, CAS, Scopus and Google Scholar

- Research which is freely available for redistribution 